\title{
Incidence and determinants of severe maternal morbidity: a transversal study in a referral hospital in Teresina, Piaui, Brazil
}

\author{
Alberto Pereira Madeiro ${ }^{1,2^{*}}$, Andréa Cronemberger Rufino ${ }^{1}$, Érica Zânia Gonçalves Lacerda ${ }^{1}$ \\ and Laís Gonçalves Brasil ${ }^{1}$
}

\begin{abstract}
Background: Maternal near miss (MNM) investigation is a useful tool for monitoring standards for obstetric care. This study evaluated the prevalence and the determinants of severe maternal morbidity (SMM) and MNM in a tertiary referral hospital in Teresina, Piauí, Brazil.

Methods: A transversal and prospective study was conducted between September 2012 and February 2013. The cases were included according to criteria established by the WHO. Odds ratio, their respective confidence intervals, and multivariate analyses were examined.

Results: Five thousand eight hundred forty one live births, 343 women with SMM, 56 cases of MNM, and 10 maternal deaths were investigated. The rate for severe maternal outcomes was 11.2 cases per 1000 live births, the rate of MNM was 9.6 cases/1000 live births, and the rate for mortality was 171.2 cases/100,000 live births. Management criteria were most frequently observed among MNM/death cases. Hypertensive diseases (86.1 \%) and hemorrhagic complications (10.0 \%) were the main determinants of MNM, but infectious abortion was the most common isolated cause of maternal death. There was a correlation between MNM/death and hospitalized more than 5 days $(p=0.023)$ and between termination of pregnancy by cesarean $(p=0.002)$ and APGAR $<7$ in the $1^{\text {st }}$ minute $(p=0.015)$.

Conclusions: SMM and MNM were quite prevalent in the population studied. Women whose condition progressed to MNM/death had a higher association with terminating pregnancy by cesarean, longer hospitalization times, and worse perinatal results. The results from the study can be useful to improve the quality of obstetric care and consequently diminish maternal mortality in the region.
\end{abstract}

\section{Background}

Despite being more common in low-income countries, maternal deaths are still a relevant public health problem among middle-income countries. There is a great disparity in the ratio of maternal mortality among countries, varying from less than 10 deaths per 100,000 live births in developed regions to $1200 / 100,000$ live births in low-income regions [1]. In Brazil the ratio of maternal mortality was 64.8/100,000 live births in 2011 [2], with worse indicators in the North (77.8/100,000 live births) and Northeast (80.8/100,000 live births) regions. The states of Maranhão

\footnotetext{
* Correspondence: madeiro@uol.com.br

'Research Center and Extension Center in Women's Health, Piaui State University, R. Olavo Bilac, 2335 - Centro/Sul, Teresina, Piauí CEP 64001-120, Brazil

${ }^{2}$ Av. Coronel Costa Araújo, 3033, Teresina, Piauí 64049-460, Brazil
}

(114.0/100,000 live births) and Piauí (101.8/100,000 live births) had highest ratios in the country [3]. Hypertensive diagnoses, hemorrhagic disorders, complications during delivery, and abortion are among the principal causes of death among Brazilian pregnant women [4].

The study of maternal mortality is a challenge for researchers and governmental agencies mainly due to a lack of reliable data. Problems such as incomplete coverage of the information system and incomplete death certificates are common in Brazil [3]. Despite to provide useful information as a measure of obstetrical care, the small number of deaths in each institution limits the use of maternal mortality indicators for surveillance of maternal health in pregnancy $[5,6]$. The search for a new indicator that could contribute to monitoring and evaluating maternal health 
brought about the development of the concept of severe maternal morbidity or near miss [7].

The term near miss was used for the first time in 1991 to refer to women who almost died from complications during the pregnancy-childbirth cycle, but who survived by chance or due to heath care they received [8]. Severe maternal morbidity represents the occurrence of a complication that could progress to maternal death, located in a spectrum between healthy pregnancy and maternal death [9]. The terms "near miss" and "severe maternal morbidity" are used interchangeably, but severe maternal morbidity reflects a less serious condition and represent a situation that precedes near miss cases in severity [10]. In the majority of cases, near miss has the same determinants as cases that end in death. Due to its greater frequency, the investigation of near miss cases allows for better and quicker understanding of the sequence of errors that lead to maternal death [11].

In the last few decades, the concept and the validity of maternal near miss have been gradually established, but controversies still exist about the criteria used to define the cases. In 2009 the World Health Organization (WHO) suggested that the investigation of the cases of near miss be part of reference monitoring used in reproductive health. Also, a research group standardized diagnostic criteria for this situation. According to these criteria, the emphasis should be focused on organic failure or dysfunction, which is identified using three categories: clinical, laboratory, and management $[12,13]$.

The prevalence of maternal near miss is variable around the world. Data from a systematic review of 46 countries demonstrate that the prevalence varies from 0.04 to $14.98 \%$, with higher rates in lower income regions in Africa and Asia [14]. A study in Holland in 2010, which evaluated 358,874 births, observed 2.4 cases of maternal near miss per 1000 live births [15]. In Brazil a multicentric study of 27 maternity reference centers, which utilized WHO criteria to identify near miss cases, registered 3.5 cases per 1000 live births [16]. Older pregnant women [17] and those with hypertensive syndromes [18] were more associated with maternal near misses.

Estimations of maternal near misses are complicated in a large country like Brazil. It is possible that the incidence and the determinants are not homogeneous among the regions that have diverse socioeconomic contexts, especially among the poorer regions. The metropolitan area of Teresina, in Piauí, Brazil, has one of the lowest indices of human development among major Brazilian cities and presents elevated rates of maternal mortality. Using WHO criteria, the present study investigated the incidence and the determinants of severe maternal morbidity and maternal near miss in a public tertiary referral maternity hospital in Teresina, where data on the topic are inexistent.

\section{Methods}

\section{Design and location of the study}

A transversal study was conducted from September 1, 2012 to February 28, 2013 to identify cases of severe maternal morbidity and maternal near miss at the Dona Evangelina Rosa Maternity in Teresina, in the Northeast of Brazil. This is the only tertiary obstetric hospital in the state of Piauí and surrounding area, providing care for the middle and low income population that depends on the public health care system. It is responsible for around 1200 monthly admissions, 1000 of which are for deliveries.

\section{Case selection}

Four trained researchers identified cases on a daily basis by actively searching through medical files. All patients who presented complications during pregnancy and delivery, up to 42 days postpartum, according to the definitions provided by the WHO Research Group on Maternal Morbidity and Mortality were included in the study [12]. The cases of severe maternal morbidity included life-threatening conditions, such as serious postpartum hemorrhage, severe preeclampsia, eclampsia, and uterine rupture. Among the cases of severe maternal morbidity, those that included at least one of the clinical, laboratory, or management criteria were characterized as near miss [12]. Table 1 presents the inclusion criteria. Two control cases were selected to one severe maternal morbidity/ near miss cases, using simple random. All patients admitted on the same day of the cases and who did not fulfil the criteria for severe maternal morbidity/near miss cases were eligible to be controls. Patients were excluded from the consideration of criteria for near miss or severe morbidity in the case of maternal death. Sociodemographic information and information related to the pregnancy, in addition to perinatal outcomes, were collected by direct case record review using a form, which had been developed and pre-tested for this study, containing 36 codified questions.

\section{Data analysis}

All of the data were put into a data bank using Microsoft Excel 2007 by two independent researchers. From the maternal outcome, maternal near miss ratio, severe maternal outcome ratio, maternal mortality ratio, maternal near miss: mortality ratio, and mortality index were calculated [12]. To verify the association between the categorical variables and the near miss/death outcome, the chi-square association test or Fisher's exact test were used (when at least one of these frequencies was less than 5). Crude and adjusted odds ratios were calculated (with $95 \%$ confidence intervals) using logistic regression. To identify independent predictive factors for maternal near miss/ death, a logistical regression model was constructed using a forward stepwise hierarchical selection, including only those variables for which $p<0.25$ in the bivariate analysis. The Hosmer and 
Table 1 Criteria to identify potentially life-threatening conditions and maternal near-miss ${ }^{a}$

\begin{tabular}{|c|}
\hline Severe maternal complications \\
\hline 1. Severe postpartum hemorrhage \\
\hline 2. Severe pre-eclampsia \\
\hline 3. Eclampsia \\
\hline 4. Sepsis or severe systemic infection \\
\hline 5. Ruptured uterus \\
\hline 6. Severe complications of abortion \\
\hline Critical interventions or intensive care unit use \\
\hline 1. Admission to intensive care unit \\
\hline 2. Interventional radiology \\
\hline 3. Laparotomy (includes hysterectomy, excludes caesarean section) \\
\hline 4. Use of blood products \\
\hline Near-miss criteria \\
\hline A. Clinical organ dysfunction \\
\hline 1. Acute cyanosis \\
\hline 2. Gasping \\
\hline 3. Respiratory rate higher than 40 or lower than 6 bpm \\
\hline 4. Shock \\
\hline 5. Cardiac arrest \\
\hline 6. Oliguria non-responsive to fluids or diuretics \\
\hline 7. Any loss of consciousness lasting for more than $12 \mathrm{~h}$ \\
\hline 8. Stroke \\
\hline 9. Uncontrollable fit or status epilepticus \\
\hline 10. Global paralysis \\
\hline 11. Jaundice in the presence of pre-eclampsia \\
\hline B. Laboratory markers \\
\hline 12. $\mathrm{O}_{2}$ saturation less than $90 \%$ for more than 60 min \\
\hline 13. $\mathrm{PaO}_{2} / \mathrm{FiO}_{2}$ less than $200 \mathrm{mmHg}$ \\
\hline 14. Creatinine more than $3.5 \mathrm{mg} / \mathrm{dL}$ \\
\hline 15. Bilirubin more than $6.0 \mathrm{mg} / \mathrm{dL}$ \\
\hline 16. pH less than 7.1 \\
\hline 17. Lactate more than $5 \mathrm{mEq} / \mathrm{L}$ \\
\hline 18. Acute thrombocytopenia ( $<50,000$ platelets) \\
\hline C. Management-based criteria \\
\hline 19. Hysterectomy after infection or hemorrhage \\
\hline 20. Use of continuous vasoactive drugs \\
\hline 21. Cardio-pulmonary resuscitation \\
\hline 22. Dialysis for acute renal failure \\
\hline 23. Any non-anesthetic intubation or ventilation \\
\hline 24. Transfusion of more than 5 units of blood or red cells \\
\hline
\end{tabular}

${ }^{\mathrm{a}}$ Terminology taken from reference [22]

Lemeshow test was used to verify the adequacy of the model. The statistical analysis was conducted using Stata ${ }^{\circ}$ (version 11) software.

\section{Ethical criteria}

The informed consent was waived by Institutional Review Board, since the data were collected directly from medical charts and without interview with patients. The study protocol was approved by the Research and Ethics Committee at the Piauí State University (CAAE 02699812.0.0000.5209).

\section{Results}

During the 6 month period of data collection, 5841 live births, 343 women with severe maternal morbidity, 56 cases of near miss $(0.95 \%$ of all deliveries), and 10 maternal deaths $(0.2 \%$ of all deliveries) were identified. Cesarean section was the mode of delivery in $58.1 \%$ of control cases, $71.4 \%$ of severe maternal morbidity cases, $87.5 \%$ of near miss cases, and $70 \%$ of maternal death cases. Cesarean sections were stated as elective in 31 cases $(22.6 \%$ of severe maternal morbidity cases, $14.3 \%$ of near miss cases and $0 \%$ of maternal death cases) and stated as emergency in 270 cases $(77.4 \%$ of severe maternal morbidity, $85.7 \%$ of near miss cases and $100 \%$ of maternal death cases). The main indications of cesarean sections among women with maternal near miss and death were listed as eclampsia/HELLP in $22 \%$, failed induction in $18.9 \%$, abruptio placentae in $16 \%$, obstructed labor in $14.7 \%$, and fetal distress in $11.5 \%$. The average length of hospitalization was 8.3 days (4.4 days to severe maternal morbidity cases, 12.5 to near miss and 10.2 to maternal deaths). Table 2 shows that the rate of severe maternal outcomes (near miss + maternal death) was 11.2 cases per 1000 live births. The maternal near miss ratio was 9.6 cases/1000 live births and the mortality

Table 2 Obstetric care quality indicators. Teresina, Piaui, Brazil

\begin{tabular}{|c|c|c|}
\hline Indicators & $n$ & Rates \\
\hline Number of live births & 5841 & - \\
\hline Women with severe maternal morbidity & 343 & - \\
\hline Women with maternal near miss & 56 & - \\
\hline Maternal deaths & 10 & - \\
\hline Maternal near miss ratio ${ }^{a}$ & - & 9.6/1000 LB \\
\hline Severe maternal outcome ratio ${ }^{b}$ & - & 11.3/1000 LB \\
\hline Maternal mortality ratio ${ }^{c}$ & - & 171.2/100,000 LB \\
\hline $\begin{array}{l}\text { Maternal near miss ratio: maternal mortality } \\
\text { ratio }^{d}\end{array}$ & - & $5.6: 1$ \\
\hline Mortality index ${ }^{e}$ & - & $15.2 \%$ \\
\hline \multicolumn{3}{|c|}{$\begin{array}{l}\text { a Maternal near miss ratio: number of cases of near miss/number of } \\
\text { live births } \times 1000 \\
\text { b Severe maternal outcome ratio: number of life threatening conditions } \\
\text { (near miss + death) / number of live births } \times 1000 \\
{ }^{c} \text { Maternal mortality ratio: number of deaths } / \text { number of live births } \times 100,000 \\
{ }^{d} \text { Maternal near miss ratio: maternal mortality ratio } \\
{ }^{\mathrm{e}} \text { Mortality index: refers "to the number of maternal deaths divided by the } \\
\text { number of women with life-threatening conditions expressed as a percentage } \\
\text { (number of deaths/number of deaths + number of near miss) }[12,22]\end{array}$} \\
\hline
\end{tabular}


ratio was 171.2 cases $/ 100,000$ live births (95\% confidence interval 143.3-193.6).

The determinants of severe maternal morbidity, near miss, and maternal deaths are exhibited in Table 3. The main causes were hypertensive (86.1\%), hemorrhagic (10.0\%) and infectious (2.9\%) disorders. Severe preeclampsia, eclampsia, and HELLP syndrome were the most frequent determinants of maternal near miss cases. In cases of death the main factors involved were hypertensive complications (40\%), hemorrhagic disorders (30\%) and infectious disorders (30\%). Of all the cases of maternal deaths, $70 \%$ used blood products, $70 \%$ had hysterectomy and $100 \%$ were admitted to Intensive Care Unit. In isolation, infectious abortion was the most common cause of maternal death, responsible for three of the ten deaths (mortality index was highest for abortion,

Table 3 Primary determinants of severe maternal morbidity $(\mathrm{SMM})^{\mathrm{a}}$, near miss ${ }^{\mathrm{b}}(\mathrm{NM})$ and maternal deaths ${ }^{c}(\mathrm{MD})$. Teresina, Piaui, Brazil

\begin{tabular}{|c|c|c|c|c|c|c|}
\hline \multirow[t]{2}{*}{ Determinants } & \multicolumn{2}{|c|}{ SMM } & \multicolumn{2}{|c|}{ NM } & \multicolumn{2}{|l|}{$\mathrm{MD}$} \\
\hline & $\mathrm{n}$ & $\%$ & $\mathrm{n}$ & $\%$ & $n$ & $\%$ \\
\hline All cases & 343 & 100 & 56 & 100 & 10 & 100 \\
\hline \multicolumn{7}{|l|}{ Hypertensive disorders $^{d}$} \\
\hline Severe pre-eclampsia & 268 & 78.1 & 17 & 30.4 & - & - \\
\hline Eclampsia & 30 & 8.7 & 10 & 17.8 & 2 & 20.0 \\
\hline HELLP syndrome & 13 & 3.8 & 10 & 17.8 & 2 & 20.0 \\
\hline \multicolumn{7}{|l|}{ Hemorrhagic disorders $^{d}$} \\
\hline Abruptio placentae & 18 & 5.2 & 6 & 10.7 & 1 & 10.0 \\
\hline Uterine atony & 2 & 0.6 & 3 & 5.3 & 2 & 20.0 \\
\hline Ectopic pregnancy & 3 & 0.9 & 1 & 1.8 & - & - \\
\hline Uterine rupture & - & - & 2 & 3.6 & - & - \\
\hline Placenta previa & - & - & 2 & 3.6 & - & - \\
\hline \multicolumn{7}{|l|}{ Infectious disorders $^{d}$} \\
\hline Chorioamnionitis & 4 & 1.2 & - & - & - & - \\
\hline Endometritis & 3 & 0.9 & - & - & - & - \\
\hline Infected abortion & 1 & 0.3 & 1 & 1.8 & 3 & 30.0 \\
\hline \multicolumn{7}{|c|}{ Other clinical conditions-surgeries } \\
\hline Sepsis after appendicitis & - & - & 1 & 1.8 & - & - \\
\hline Diabetic ketoacidosis & - & - & 1 & 1.8 & - & - \\
\hline Acute pyelonephritis & 1 & 0.3 & 1 & 1.8 & - & - \\
\hline Cardiomyopathy & - & - & 1 & 1.8 & - & - \\
\hline
\end{tabular}

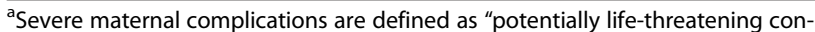
ditions" (disease-specific, intervention specific and organ dysfunction-based criteria) $[12,22]$

${ }^{b}$ Near miss refers "to a woman who nearly died but survived a complication that occurred during pregnancy, childbirth or within 42 days of termination of pregnancy" $[12,22]$

'Maternal death is "the death of a woman while pregnant or within 42 days of termination of pregnancy" $[12,22]$

${ }^{\mathrm{d}}$ Mortality index for the different disease categories: hypertensive disorders (9.7\%), hemorrhagic disorders (17.6\%) and infectious disorders (75\%)
$75 \%)$. Other non-obstetric clinical-surgical conditions were implied in complications for five women.

Table 4 shows the cases of maternal near miss and death according to the criteria established by the WHO. All of the cases of maternal death included at least one of the criteria for near miss. Shock was the most common clinical criteria, while the presence of thrombocytopenia was the most frequent of the laboratory criteria. The use of vasoactive drugs, hysterectomy, and transfusion of more than five units of concentrated red blood cells were the most prevalent management criteria.

Women in the near miss/death category were more frequently associated with hospitalization of more than 5 days $(p=0.023)$, termination of the pregnancy by cesarean $(p=$ $0.002)$ and APGAR $<7$ during the $1^{\text {st }}$ minute $(p=0.015)$. Among the near miss/death cases, there were 20 postpartum hysterectomies (32.3\%) (Table 5 ). In the multivariate

Table 4 Near miss (NM) and maternal deaths according to the WHO criteria. Teresina, Piaui, Brazil

\begin{tabular}{|c|c|c|c|c|}
\hline \multirow[t]{2}{*}{ Criteria } & \multicolumn{2}{|c|}{ NM } & \multicolumn{2}{|c|}{ Deaths } \\
\hline & $\mathrm{N}$ & $\%$ & $\mathrm{n}$ & $\%$ \\
\hline All cases & 56 & 100 & 10 & 100 \\
\hline Presence of 1 criteria & 33 & 58.9 & 1 & 10,0 \\
\hline Presence of 2 criteria & 12 & 21.4 & 1 & 10,0 \\
\hline Presence of 3 or more criteria & 11 & 19.7 & 8 & 80.0 \\
\hline \multicolumn{5}{|l|}{ Clinical criteria $^{a}$} \\
\hline Shock & 12 & 21.4 & 4 & 40.0 \\
\hline Oliguria unresponsive to fluid/diuretics & 1 & 1.8 & 1 & 10.0 \\
\hline Loss of consciousness $\geq 12 \mathrm{~h}$ & 2 & 3.6 & 2 & 20.0 \\
\hline Stroke & 1 & 1.8 & - & - \\
\hline Reentrant seizures & 1 & 1.8 & - & - \\
\hline \multicolumn{5}{|l|}{ Laboratory-based criteria ${ }^{b}$} \\
\hline Oxygen saturation $<90 \%$ for $\geq 60 \mathrm{~min}$ & 1 & 1.8 & 2 & 20.0 \\
\hline Creatinine $\geq 3.5 \mathrm{mg} / \mathrm{dl}$ & 3 & 5.3 & 2 & 20.0 \\
\hline Total bilirrubine $\geq 6.0 \mathrm{mg} / \mathrm{dl}$ & - & - & 2 & 20.0 \\
\hline Acute thrombocytopenia $(<50.000)$ & 10 & 17.8 & 2 & 20.0 \\
\hline $\begin{array}{l}\text { Loss of consciousness and presence of } \\
\text { glycosuria/ketonuria }\end{array}$ & 1 & 1.8 & - & \\
\hline \multicolumn{5}{|l|}{ Management-based criteria } \\
\hline Continuous use of vasoactive drugs & 11 & 19.6 & 6 & 60.0 \\
\hline Hysterectomy following infection or bleeding & 15 & 26.8 & 4 & 40.0 \\
\hline $\begin{array}{l}\text { Transfusion of concentrated red blood cells } \\
\text { ( } \geq 5 \text { units) }\end{array}$ & 10 & 17.8 & 3 & 30.0 \\
\hline $\begin{array}{l}\text { Intubation and mechanical ventilation for } \\
\geq 60 \mathrm{~min}\end{array}$ & 6 & 10.7 & 6 & 60.0 \\
\hline Dialysis for acute renal failure & 2 & 3.6 & 1 & 10.0 \\
\hline Cardio-pulmonary resuscitation & 3 & 5.3 & 1 & 10.0 \\
\hline
\end{tabular}

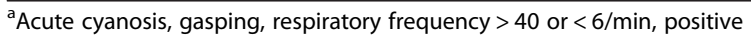
bedside coagulation test, loss of consciousness and absence of pulse, jaundice in the presence of pre-eclampsia were not found

${ }^{\mathrm{b}} \mathrm{PaO} 2 / \mathrm{FiO} 2<200 \mathrm{mmHg}, \mathrm{pH}<7.1$, lactate $>5 \mathrm{mg} / \mathrm{dl}$ were not found 
Table 5 Sociodemographic and clinical variables for severe maternal morbidity (SMM) and near miss (NM)/death. Teresina, Piaui, Brazil

\begin{tabular}{|c|c|c|c|c|c|c|c|c|}
\hline \multirow[t]{2}{*}{ Variables } & \multicolumn{2}{|c|}{ SMM $(n=343)$} & \multicolumn{2}{|c|}{ NM/Death $(n=66)$} & \multicolumn{2}{|c|}{$C C^{a}(n=824)$} & \multirow{2}{*}{$\begin{array}{l}\text { SMM vs. } C^{b} \\
\text { OR (Cl } 95 \%)\end{array}$} & \multirow{2}{*}{$\begin{array}{l}\text { NM/Death vs. CC } \\
\text { OR (Cl } 95 \%)\end{array}$} \\
\hline & $\mathrm{N}$ & $\%$ & $\mathrm{~N}$ & $\%$ & $\mathrm{~N}$ & $\%$ & & \\
\hline \multicolumn{9}{|c|}{ Age $<20$ years } \\
\hline No & 266 & 77.5 & 49 & 74.2 & 654 & 79.4 & 1.0 & 1.0 \\
\hline Yes & 77 & 22.5 & 17 & 25.8 & 170 & 20.6 & $1.1(0.3-1.6)$ & $1.3(0.5-1.9)$ \\
\hline \multicolumn{9}{|c|}{ Education $<8$ years } \\
\hline No & 209 & 60.9 & 41 & 62.1 & 505 & 61.3 & 1.0 & 1.0 \\
\hline Yes & 134 & 39.1 & 25 & 37.9 & 319 & 38.7 & $1.1(0.7-1.9)$ & $0.9(0.6-1.4)$ \\
\hline \multicolumn{9}{|l|}{ Partner } \\
\hline Yes & 272 & 79.3 & 51 & 77.3 & 629 & 76.3 & 1.0 & 1.0 \\
\hline No & 71 & 20.7 & 15 & 22.7 & 195 & 23.7 & $0.8(0.5-2.3)$ & $0.9(0.6-1.8)$ \\
\hline \multicolumn{9}{|c|}{ Number of pregnancies $\geq 4$} \\
\hline No & 295 & 86.0 & 57 & 86.4 & 722 & 87.6 & 1.0 & 1.0 \\
\hline Yes & 48 & 14.0 & 9 & 13.6 & 102 & 12.4 & $1.1(0.4-1.9)$ & $1.1(0.6-1.7)$ \\
\hline \multicolumn{9}{|c|}{ Previous cesarean } \\
\hline No & 89 & 25.9 & 21 & 31.8 & 264 & 32.0 & 1.0 & 1.0 \\
\hline Yes & 254 & 74.1 & 45 & 68.2 & 560 & 68.0 & $1.3(0.7-2.3)$ & $1.0(0.8-2.0)$ \\
\hline \multicolumn{9}{|c|}{ Gestational age $<37$ weeks } \\
\hline No & 172 & 50.6 & 28 & 45.2 & 432 & 54.5 & 1.0 & 1.0 \\
\hline Yes & 168 & 49.4 & 34 & 54.8 & 360 & 45.5 & $1.2(0.6-1.3)$ & $1.5(0.8-2.3)$ \\
\hline \multicolumn{9}{|c|}{ Prenatal consultations $<6$} \\
\hline No & 165 & 49.4 & 31 & 49.2 & 402 & 50.4 & 1.0 & 1.0 \\
\hline Yes & 169 & 50.6 & 32 & 50.8 & 396 & 49.6 & $1.0(0.6-1.6)$ & $1.0(0.7-2.1)$ \\
\hline \multicolumn{9}{|c|}{ Comorbidities } \\
\hline No & 265 & 77.3 & 53 & 80.3 & 650 & 78.9 & 1.0 & 1.0 \\
\hline Yes & 78 & 22.7 & 13 & 19.7 & 174 & 21.1 & $1.0(0.5-1.5)$ & $0.9(0.4-1.9)$ \\
\hline \multicolumn{9}{|c|}{ Hysterectomy $^{d}$} \\
\hline No & 341 & 99.4 & 46 & 69.7 & 824 & 100.0 & - & - \\
\hline Yes & 2 & 0.6 & 20 & 30.3 & - & - & & \\
\hline \multicolumn{9}{|c|}{ Cesarean section (current delivery) } \\
\hline No & 91 & 27.1 & 5 & 8.2 & 322 & 40.2 & 1.0 & 1.0 \\
\hline Yes & 245 & 72.9 & 56 & 91.8 & 479 & 59.8 & $6.2(1.7-11.3)^{*}$ & $8.3(1.9-13.1)^{*}$ \\
\hline \multicolumn{9}{|c|}{ Length of hospital stay ( $\geq 5$ days) } \\
\hline No & 160 & 46.6 & 22 & 33.3 & 768 & 93.2 & 1.0 & 1.0 \\
\hline Yes & 183 & 53.4 & 44 & 66.7 & 56 & 6.8 & $6.7(1.5-8.4)^{*}$ & $9.6(1.7-12.8)^{*}$ \\
\hline \multicolumn{9}{|c|}{ APGAR 1st minute $<7$} \\
\hline No & 277 & 85.5 & 39 & 73.6 & 744 & 93.5 & 1.0 & 1.0 \\
\hline Yes & 47 & 14.5 & 14 & 26.4 & 52 & 6.5 & $2.5(1.7-4.9)^{*}$ & $4.6(1.9-5.4)^{*}$ \\
\hline \multicolumn{9}{|c|}{ APGAR 5th minute $<7$} \\
\hline No & 313 & 96.6 & 50 & 94.3 & 770 & 96.7 & 1.0 & 1.0 \\
\hline Yes & 11 & 3.4 & 3 & 5.7 & 26 & 3.3 & $1.0(0.5-2.6)$ & $1.2(0.7-2.2)$ \\
\hline \multicolumn{9}{|c|}{ Fetal weight $<2500 \mathrm{~g}$} \\
\hline No & 195 & 58.4 & 29 & 50.0 & 445 & 54.6 & 1.0 & 1.0 \\
\hline Yes & 139 & 41.6 & 29 & 50.0 & 370 & 45.4 & $0.8(0.5-1.5)$ & $1.3(0.8-1.8)$ \\
\hline
\end{tabular}


Table 5 Sociodemographic and clinical variables for severe maternal morbidity (SMM) and near miss (NM)/death. Teresina, Piaui, Brazil (Continued)

\begin{tabular}{llllllll}
\hline Neonatal death & & & & & & \\
No & 299 & 89.5 & 47 & 81.0 & 715 & 87.7 & 1.0 \\
Yes & 35 & 10.5 & 11 & 19.0 & 100 & 12.3 & $0.8(0.4-1.4)$ \\
\hline
\end{tabular}

${ }^{*} p$-value $<0.05$ (chi-square association test/Fisher's exact test)

${ }^{\text {a }}$ Control cases

${ }^{\mathrm{b}}$ Severe maternal morbidity cases versus control cases

${ }^{\mathrm{c}}$ Near miss/deaths cases versus control cases

${ }^{\mathrm{d}}$ Criterion for maternal near miss

model, only cesarean section $(p=0.019)$ remained as a predictive factor of near miss/death (Table 6).

\section{Discussion}

This is the first hospital-based study about maternal near miss conducted in the city of Teresina, in the Northeast of Brazil. The Dona Evangelina Rosa Maternity is the only unit with obstetric intensive care in the region, serving an atrisk population in an area with around 5 million inhabitants. The study utilized the criteria (clinical, laboratory, and management) proposed by the WHO in 2009, based on the presence of dysfunction or organic failure [12]. The management-based criteria were observed most frequently in the cases of near miss and the only ones indicated in all of the deaths. Other studies also show that the WHO criteria are good markers for identifying maternal near miss due to the fact that they increase the possibility of detection in the most serious cases and in those cases with greater risk for death [16-19]. The near miss cases, since they presented similar characteristics as those of maternal death, can offer important information that can be used to improve obstetric care.

Table 6 Multivariate analysis* of the predictive factors for near miss/death. Teresina, Piaui, Brazil

\begin{tabular}{|c|c|c|c|c|}
\hline Variable & $\mathrm{OR}^{\mathrm{a}}$ & $\mathrm{OR}_{\mathrm{adj}} \mathrm{b}^{\mathrm{b}}$ & $\begin{array}{l}\mathrm{Cl} 95 \%{ }^{\mathrm{c}} \\
\left(\mathrm{OR}_{\mathrm{adj}}\right)\end{array}$ & $p$-value ${ }^{* *}$ \\
\hline \multicolumn{5}{|c|}{$\begin{array}{l}\text { Termination of pregnancy } \\
\text { (mode of birth) }\end{array}$} \\
\hline Vaginal & Ref. & Ref. & $1.3-16.5$ & 0.019 \\
\hline Cesarean section & 4.2 & 4.2 & & \\
\hline \multicolumn{5}{|l|}{ APGAR 1st minute $<7$} \\
\hline No & Ref. & Ref. & $0.8-3.9$ & 0.183 \\
\hline Yes & 2.1 & 1.7 & & \\
\hline \multicolumn{5}{|c|}{ Length of hospital stay } \\
\hline$<5$ & Ref. & Ref. & $0.9-4.0$ & 0.099 \\
\hline 5 or more & 1.7 & 1.9 & & \\
\hline $\begin{array}{l}\text { *Hosmer and Lemesho } \\
{ }^{* *} \text { Chi-square test } \\
{ }^{\text {a } C r u d e ~ o d d s ~ r a t i o ~} \\
{ }^{b} \text { Odds ratio adjusted fo } \\
{ }^{c} \text { Confidence interval at }\end{array}$ & r varia & $s$ in the $t$ & & \\
\hline
\end{tabular}

The incidence of maternal near miss in this study (9.6/ 1000 live births) was higher than that found in hospitalbased studies conducted in other states, as Sao Paulo and Sergipe, which reported, respectively, near miss rates of 4.4/1000 live births and 4.7/1000 live births [19, 20]. A systematic review in 2012 showed that the incidence of near miss in Latin America and the Caribbean oscillated between 0.34 and $4.93 \%$, varying mainly according to the type of criteria used to define the cases [14]. Studies that utilized Waterstone's criteria, for example, tend to include situations with a lower risk of death and, as such, produce higher rates of near miss $[12,21]$. The ratio of maternal mortality for the institution (171.2/100,000 live births) was also higher than that found in Brazil in 2011 (64.8/100,000 live births), which was $164 \%$ higher than the national average [3]. On the other hand, the near miss/ death relationship is compatible with data that show that near miss is almost four times more frequent than cases of maternal death; therefore, it is a good parameter for studying cases in which the risk of progressing to death are higher [12-14].

In the present study, the most frequent determinants of severe maternal morbidity were hypertensive disorders, similar to that found in other regions in the country and other developing countries $[14,17,18,20]$. Nearly $1 / 4$ of maternal deaths in Latin America and the Caribbean are the result of hypertensive complications [10]. In Brazil, a multicentric study in 27 referral hospitals revealed that hypertensive diseases were responsible for $70 \%$ of the cases of severe maternal morbidity, with the ratio of near miss at 4.2/1000 live births [18]. Among the cases of hypertensive complications, $66 \%$ progressed to near miss and $40 \%$ progressed to death, suggesting a delay in the access to care, delayed disease recognition, inadequate or delayed use of antihypertensives and magnesium sulfate. In Brazil, a recent study showed that magnesium sulfate was used in less than $70 \%$ of cases of severe maternal morbidity [18]. Mainly for low-income regions, the reduction of mortality from hypertensive disorders is associated with an improvement in the quality of obstetric care, women's access to hospitalization, continuing education for healthcare professionals, and a greater availability of beds in intensive care units [10, 22, 23]. 
Hemorrhagic causes represent $25 \%$ of the near miss cases and $30 \%$ of those that progress to death, with an emphasis on placental abruption and uterine atony. Similar data were found in two other national studies $[19,20]$. In Limeira, a city in the Southeast of the country, hemorrhagic complications contributed to $39.5 \%$ of the near miss cases and $40 \%$ of the deaths [19]. While in Aracaju, in the Northeast, the principal determinant of maternal death was hemorrhage in $41.2 \%$ of the cases [20]. A recent multicentric study in 352 health facilities in 28 countries showed that, among the cases of hemorrhagic complications that progressed to a severe maternal outcome (near miss + death), the risk was greater among women who have had less than five years of education, reside in low-income regions, have had more than three pregnancies, had a cesarean, and who had not received prophylactic uterotonic medication [24].

When compared with other causes, abortion was responsible for a small number of cases of severe maternal morbidity and near miss. Nevertheless, it is important to note the fact that in isolation, it was the most frequent determinant (three out of ten) of the cases that evolved to death. Despite the fact that it was not possible to distinguish between spontaneous and induced abortion, infectious complication is a well-known cause of morbidity and mortality when the abortion was induced in an unsafe manner $[1,25]$. The frequency of endometritis and sepsis after unsafe abortions has decreased since misoprostol became the predominant method of abortion for Brazilian women $[26,27]$. Nevertheless, the use of pills that do not contain the active ingredient or insufficient doses, besides a delay in going to the hospital for fear of being denounced to the police, can contribute to the persistence of hemorrhagic post abortion complications and infections [28, 29]. Young women who do not have a married partner and who have abortions after 14 weeks of pregnancy are at the greatest risk of near miss or death [30].

Other national studies show that women who are older, have less education, have fewer pre-natal consultations, without a married partner, or previous cesarean have the greatest risk of near miss [17-20,31]. Nevertheless, this was not observed in the present study. The group of women in the maternal near miss/death group only exhibited a greater association with hospitalization greater than 5 days, higher frequency of cesareans in the current pregnancy, and worse neonatal results. The need for interventions to manage severe ill patients can explain a longer period of hospitalization rather than a potential cause of severe morbidity/near miss. Similarly, a greater presence of APGAR $<7$ at the 1st minute in the near miss/death group can be understood as a reflection of the greater severity of obstetric illness and of the need to interrupt the pregnancy earlier, a fact which has been observed in other national studies [17-19].
There are controversies in the literature as to whether a cesarean in the current pregnancy can be considered to be a risk for severe maternal morbidity/near miss or, to the contrary, a confounding risk variable. On one hand, interrupting the pregnancy with a cesarean increases the prevalence of infection, hemorrhage, and other complications, which can increase the chance of severe maternal morbidity/near miss [19, 20, 31]. Data from the Ministry of Health show that women who have had a cesarean have 3.5 times greater chance of dying and 5 times greater chance of postpartum infection than those who have a vaginal delivery [32]. On the other hand, the greater frequency of cesareans in this group can be justified by the intrinsic seriousness of near miss cases, which require interrupting the pregnancy earlier to impede the progress of the illness. Another fact that should be recalled is that Brazil has one of the highest rates of cesareans in the world, many times without justification, surpassing half of all deliveries (52\%) in 2010 [32]. In this study, it is possible that high rate of cesarean section was the severe morbidity in itself due to the urgency to resolve the pregnancy, given $89.7 \%$ of them were emergency cesarean sections.

There was a number of limitations to this study that must be considered. First, considering that the Dona Evangelina Rosa Maternity is the only unit in the region that has an obstetric intensive care unit, it is possible that there has been a selection bias. The large concentration of pregnant women with previous comorbidities and obstetric complications might have overestimated the indicators. Secondly, the small number of cases may have contributed why no variables of statistical significance were found to be associated with maternal near miss or death. A future study with more large series could to guarantee statistical power to identify risk factors in the women investigated. Thirdly, the study did not evaluate if the near miss cases occurred due to a delay in seeking medical assistance, difficulty reaching the hospital, or a delay in receiving adequate medical treatment. The near miss development process can be interrupted if the fragility of the system and of health services is recognized [33]. Despite these limitations, one would hope that upon filling in the gaps for the incidence and determinants of severe maternal morbidity and near miss in Teresina, the data from this study can help to implement preventative measures and offer better standards of obstetric care.

\section{Conclusion}

The results show that serious maternal morbidity and near miss affected a large number of women at the Dona Evangelina Rosa Maternity in Teresina during the period in which this study was conducted. In addition, the ratio of mortality encountered was also high, with percentages higher than the national average. Hypertensive diseases 
were the most frequent cause of serious maternal morbidity and near miss, but infectious abortion was the most common primary isolated determinant of maternal deaths, suggesting that delays may occur in provision appropriate care. Except for cesarean section, no risk factors were identified for near miss. The monitoring of severe maternal morbidity/ near miss cases may allow for evaluation of adequate obstetrical care. The data from the study can be useful to help care providers to recognize early high risk pregnancies and develop interventions for the prevention of severe maternal morbidity.

\section{Abbreviations}

MNM: Maternal near miss; SMM: Severe maternal morbidity; WHO: World Health Organization; OR: Odds ratio; Cl: Confidence interval; HELLP: Acronym of the three main features of the syndrome: hemolysis, elevated liver enzymes, and low platelets count.

\section{Competing interests}

The authors declare that they have no competing interests.

\section{Authors' contributions}

APM participated in the conception of the project, data collection and analysis, writing the article, and approving the final version. ACR collaborated in the conception of the project, data analysis, writing and approval of the final version of the article. EZGL and LGB contributed to the collection and analysis of data, critical review and approval of the final version of the article.

\section{Author's information}

Alberto Pereira Madeiro, Andréa Cronemberger Rufino: Professor, Research Center and Extension Center in Women's Health, Piauí State University. Érica Zânia Gonçalves Lacerda, Laís Gonçalves Brasil: Medical students, Research Center and Extension Center in Women's Health, Piauí State University.

\section{Acknowledgements}

The authors gratefully acknowledge the support of Piauí State University.

Received: 21 August 2014 Accepted: 2 September 2015

Published online: 07 September 2015

\section{References}

1. Hogan MC, Foreman KJ, Naghavi M, Ahn SY, Wang M, Makela SM, et al. Maternal mortality for 181 countries, 1980-2008: a systematic analysis of progress towards Millennium Development Goal 5. Lancet. 2010;375(9726):1609-23.

2. Mortality indicators. Maternal mortality rate. Brasilia: Ministry of Health. 2011. http://tabnet.datasus.gov.br/cgi/idb2012/C03b.htm. Accessed 15 October 2014.

3. Szwarcwald CL, Escalante JJC, Rabello Neto DL, Souza Jr PRB, Victora CG Estimation of maternal mortality rates in Brazil, 2008-2011. Cad Saude Publica. 2014;30(suppl):S71-83.

4. Laurenti R, Jorge MHPM, Gotlieb SLD. Maternal mortality in Brazilian State Capitals: some characteristics and estimates for an adjustment factor. Rev Bras Epidemiol. 2004;7(4):449-60.

5. Deneux-Tharaux C, Berg C, Bouvier-Colle MH, Gissler M, Harper M, Nannini A, et al. Underreporting of pregnancy-related mortality in the United States and Europe. Obstet Gynecol. 2005;106(4):684-92.

6. Pattinson RC, Buchmann E, Mantel G, Schoon M, Rees H. Can enquiries into severe acute maternal morbidity act as a surrogate for maternal death enquiries? BJOG. 2003;110(10):889-93.

7. Souza JP, Cecatti JG, Parpinelli MA, Sousa MH, Serruya SJ. Systematic review of near miss maternal morbidity. Cad Saude Publica. 2006;22(2):255-64.

8. Stones W, Lim W, Al-Azzawi F, Kelly M. An investigation of maternal morbidity with identification of life-threatening near miss episodes. Health Trends. 1991;23(1):13-5.

9. Souza JP, Cecatti JG, Faúndes A, Morais SS, Villar J, Carroli G, et al. Maternal near miss and maternal death in the World Health Organization's 2005 global survey on maternal and perinatal health. Bull World Health Organ. 2010;88(2):113-9.

10. Geller SE, Rosenberger D, Cox SM, Brown ML, Simonson L, Driscoll CA, et al. The continuum of maternal morbidity and mortality: factors associated with severity. Am J Obstet Gynecol. 2004;191(3):939-44.

11. Pattinson RC, Hall M. Near misses: a useful adjunct to maternal death enquires. Br Med Bull. 2003;67(1):231-43.

12. Say L, Souza JP, Pattinson RC. Maternal near miss - towards a standard tool for monitoring quality of maternal health care. Best Pract Res Clin Obstet Gynaecol. 2009;23(3):287-96.

13. Pattinson R, Say L, Souza JP, van den Broek N, Rooney C. WHO maternal death and near-miss classifications. Bull World Health Organ. 2009:87(10):734

14. Tunçalp O, Hindin MJ, Souza JP, Chou D, Say L. The prevalence of maternal near miss: a systematic review. BJOG. 2012;119(6):653-61.

15. Zwart JJ, Dupuis JRO, Richters A, Öry F, van Roosmalen J. Obstetric intensive care unit admission: a 2-year nationwide population-based cohort study. Intensive Care Med. 2010;36(2):256-63.

16. Souza JP, Cecatti JG, Haddad SM, Parpinelli MA, Costa ML, Katz L, et al. The WHO maternal near-miss approach and the maternal severity index model (MSI): tools for accessing the management of severe maternal morbidity. PLoS One. 2012;7(8), e44129.

17. Oliveira Jr FC, Surita FG, Pinto e Silva JL, Cecatti JG, Parpinelli MA, Haddad SM, et al. Severe maternal morbidity and maternal near miss in the extremes of reproductive age: results from a national cross-sectional multicenter study. BMC Pregnancy Childbirth. 2014;14:77.

18. Zanette E, Parpinelli MA, Surita FG, Costa ML, Haddad SM, Sousa MH, et al. Maternal near miss and death among women with severe hypertensive disorders: a Brazilian multicenter surveillance study. Reprod Health. 2014;11(1):4

19. Lotufo FA, Parpinelli MA, Haddad SM, Surita FG, Cecatti JG. Applying the new concept of maternal near-miss in an intensive care. Clinics. 2012;67(3):225-30.

20. Galvão LP, Alvim-Pereira F, Mendonça CMM, Menezes FEF, Góis KAN, Ribeiro Jr RF, et al. The prevalence of severe maternal morbidity and near miss and associated factors in Sergipe, Northeast Brazil. BMC Pregnancy Childbirth. 2014;14:25.

21. Waterstone W, Bewley S, Wolfe C. Incidence and predictors of severe obstetric morbidity: case-control study. BMJ. 2001;322(7294):1089-94.

22. World Health Organization. Evaluating the quality of care for severe pregnancy complications: the WHO near-miss approach for maternal health. Geneva: World Health Organization; 2011.

23. Goldenberg RL, McClure EM, MacGuire ER, Kamath BD, Jobe AH. Lessons for low-income regions following the reduction in hypertension-related maternal mortality in high-income countries. Int J Obstet Gynecol. 2011;113(2):91-5.

24. Sheldon WR, Blum J, Vogel JP, Souza JP, Gülmezoglu AM, Winikoff B, et al. Postpartum haemorrhage management, risks, and maternal outcomes: findings from the World Health Organization Multicountry Survey on Maternal and Newborn Health. BJOG. 2014;121 Suppl. 1:5-13.

25. Adler AJ, Filippi V, Thomas SL, Ronsmans C. Incidence of severe acute maternal morbidity associated with abortion: a systematic review. Trop Med Int Health. 2012;17(2):177-90.

26. Faúndes A, Santos LC, Carvalho M, Gras C. Post-abortion complications after interruption of pregnancy with misoprostol. Adv Contrac. 1996;12(1):1-9.

27. Santana DS, Cecatti JG, Parpinelli MA, Haddad SM, Costa ML, Sousa MH, et al. Severe maternal morbidity due to abortion prospectively identified in a surveillance network in Brazil. Int J Obstet Gynecol. 2012;110(1):44-8.

28. Diniz D, Madeiro A. Cytotec and abortion: the police, the vendors and women. Cienc Saude Colet. 2012;17(7):1795-803.

29. Zamberlin N, Romero M, Ramos S. Latin American women's experiences with medical abortion in settings where abortion is legally restricted. Reprod Health. 2012;9:34.

30. Dragoman M, Sheldon WR, Qureshi Z, Blum J, Winikoff B, Ganatra B, et al. Overview of abortion cases with severe maternal outcomes in the WHO Multicountry Survey on Maternal and Newborn Health: a descriptive analysis. BJOG. 2014;121 Suppl. 1:25-31.

31. Pacheco AJ, Katz L, Souza AS, Amorim MA. Factors associated with severe maternal morbidity and near miss in the Sao Francisco Valley, Brazil: a retrospective, cohort study. BMC Pregnancy Childbirth. 2014;14:91. 
32. Cesarean sections in Brazil: situation in 2010, trends and perspectives. Brasilia: Ministry of Health. 2011. http://bvsms.saude.gov.br/bvs/publicacoes/ saude_brasil_2011.pdf. Accessed 22 October 2014.

33. Pacagnella RC, Cecatti JG, Osis MJ, Souza JP. The role of delays in severe maternal morbidity and mortality: expanding the conceptual framework. Reprod Health Matter. 2012;20(39):155-63.

Submit your next manuscript to BioMed Central and take full advantage of:

- Convenient online submission

- Thorough peer review

- No space constraints or color figure charges

- Immediate publication on acceptance

- Inclusion in PubMed, CAS, Scopus and Google Scholar

- Research which is freely available for redistribution 